Article

\title{
The Ruminal Microbiome and Metabolome Alterations Associated with Diet-Induced Milk Fat Depression in Dairy Cows
}

\author{
Hongbo Zeng ${ }^{1,2,3,4,5}$, Changzheng Guo ${ }^{1,2,3,4,5}$, Daming Sun ${ }^{1,2,3,4,5}$, \\ Hossam-eldin Seddik $1,2,3,4,5$ and Shengyong Mao 1,2,3,4,5,* (iD \\ 1 Laboratory of Gastrointestinal Microbiology, College of Animal Science and Technology, \\ Nanjing Agricultural University, Nanjing 210095, China \\ 2 Jiangsu Key Laboratory of Gastrointestinal Nutrition and Animal Health, Nanjing Agricultural University, \\ Nanjing 210095, China \\ 3 National Experimental Teaching Demonstration Center of Animal Science, Nanjing Agricultural University, \\ Nanjing 210095, China \\ 4 National Center for International Research on Animal Gut Nutrition, Nanjing Agricultural University, \\ Nanjing 210095, China \\ 5 Joint International Research Laboratory of Animal Health and Food Safety, Nanjing Agricultural University, \\ Nanjing 210095, China \\ * Correspondence: maoshengyong@njau.edu.cn; Tel.: +86-25-8439-5523; Fax: +86-25-8439-5314
}

Received: 3 June 2019; Accepted: 20 July 2019; Published: 23 July 2019

\begin{abstract}
Milk fat depression (MFD) syndrome represents a significant drawback to the dairy industry. The aim of this study was to unravel the ruminal metabolome-microbiome interaction in response to diet-induced MFD in dairy cows. Twelve healthy second parity Holstein dairy cows (days in milk $(\mathrm{DIM})=119 \pm 14)$ were randomly assigned into control $(\mathrm{CON}, n=6)$ group and treatment $(\mathrm{TR}, n=6)$ group. Cows in TR group received a high-starch total mixed ration (TMR) designed to induce an MFD syndrome. Decreased milk fat yield and concentration in TR cows displayed the successful development of MFD syndrome. TR diet increased the relative abundance of Prevotella and decreased the relative abundance of unclassified Lachnospiraceae, Oribacterium, unclassified Veillonellaceae and Pseudobutyrivibrio in ruminal fluid. Metabolomics analysis revealed that the ruminal fluid content of glucose, amino acids and amines were significantly increased in TR cows compared with CON cows. Correlation analysis revealed that the concentration of amines and amino acids were highly correlated with the abundance of Oribacterium, Pseudobutyrivibrio, RC9_gut_group, unclassified BS11_gut_group and Selenomonas. In general, these findings revealed that TR diet reduced the rumination time and altered rumen fermentation type, which led to changes in the composition of ruminal microbiota and metabolites, and caused MFD.
\end{abstract}

Keywords: milk fat depression; metabolome; microbiome; rumen

\section{Introduction}

Milk fat depression (MFD), defined as the reduction in the yield and percentage of milk fat, is a serious problem in dairy industry [1]. MFD is a classic example of the interactions among dietary nutrients, the gastrointestinal microbiota and tissue physiology [2]. There have been various proposed theories to explain the occurrence of MFD in dairy industry, and the most widely accepted theory was that under the condition of large-scale dairy farm, dairy cows fed high concentrate diets had a decrease of milk fat because of the changes in the concentration of volatile fatty acids (VFA) and the alteration of microbiota in the rumen [3]. Urrutia et al. [4] reported that both the butyrate and 
acetate concentrations and ratio of acetate to propionate in the rumen are related to the milk fat synthesis. The accumulation of VFA is closely related to microbial fluctuations, thus the changes in VFA in the case of MFD indicated an association between the ruminal microbiota and MFD, previous studies showed that the MFD was related to a decrease of Bacteroidetes and an increase of Firmicutes and Actinobacteria. While the unclassified Lachnospiraceae, Butyrivibrio, Bulleidia and Coriobacteriaceae bacteria taxa were higher in MFD cattle [3]. Weimer, Stevenson and Mertens [1] reported a shift in ruminal bacterial community composition in lactating dairy cows encountering MFD. These studies proposed the ruminal bacterial community composition can be altered in MFD cattle, however, the relationships between ruminal metabolites and microbiota are not clearly elucidated. Numerous evidences indicated that rumen metabolic disorders related with changes in the ruminal microbiota are important factors for physical disorders in dairy cows [5,6]. Therefore, we need to explore the composition and alterations of ruminal metabolites in MFD cattle which can reveal microbial mediated metabolic processes. Furthermore, it can provide comprehensive associations between the ruminal microbiome and metabolome under conditions of diet-induced MFD.

In the present study, we hypothesized that there is a shift in the global profile of ruminal microbiome and metabolome in dairy cows with MFD induced by a pelleted high-starch diet. Thus, the objective of our research is to establish a model of dairy cows encountering MFD and investigate the associations between ruminal microbiome and metabolome.

\section{Results}

\subsection{Dry Matter Intake (DMI), Milk Yield and Composition}

There was no significance in DMI and milk yield between both groups (Table 1). However, compared with CON group, the milk fat percentage and milk fat yield were lower $(P=0.001$, $P<0.001)$, while the milk lactose percentage was higher $(P=0.028)$ in TR group. No significant differences were observed in milk lactose, protein percentage and yield between CON and TR groups.

Table 1. Dry matter intake and milk component yields and concentrations of control $\left(\mathrm{CON}^{1}\right)$ and treatment $\left(\mathrm{TR}^{2}\right)$ groups.

\begin{tabular}{ccccc}
\hline Item & CON & TR & SEM & $P$-Value \\
\hline DMI $(\mathrm{Kg} / \mathrm{d})$ & 23.72 & 20.82 & 0.68 & 0.639 \\
Milk yield $(\mathrm{Kg} / \mathrm{d})$ & 35.72 & 31.36 & 1.41 & 0.136 \\
Protein yield $(\mathrm{Kg} / \mathrm{d})$ & 1.10 & 0.99 & 0.04 & 0.172 \\
Lactose yield $(\mathrm{Kg} / \mathrm{d})$ & 1.78 & 1.60 & 0.07 & 0.182 \\
Fat yield, $(\mathrm{Kg} / \mathrm{d})$ & 1.24 & 0.77 & 0.04 & $<0.001$ \\
Protein $(\%)$ & 3.10 & 3.15 & 0.02 & 0.067 \\
Lactose $(\%)$ & 5.00 & 5.11 & 0.02 & 0.028 \\
Fat $(\%)$ & 3.47 & 2.42 & 0.09 & 0.001 \\
\hline
\end{tabular}

${ }^{1} \mathrm{CON}\left(\right.$ control group) $=$ dairy cows fed total mixed ration (TMR). ${ }^{2} \mathrm{TR}($ treatment group) $=$ dairy cows fed pelleted high-starch diet.

\subsection{Fermentation Parameters and Animal Behavior}

The concentration of propionate and propionate percentage were higher $(P=0.002, P<0.001)$ in TR group compared with CON group (Table 2). There was no significance in lactic acid concentration and total VFA concentration between both groups. The ruminal $\mathrm{pH}$, acetate percentage, butyrate percentage and acetate to propionate ratio were lower $(P=0.011, P=0.005, P=0.018, P=0.001)$ in TR group compared with CON group. 
Table 2. Ruminal fermentation parameters of $\mathrm{CON}^{1}$ and $\mathrm{TR}^{2}$ groups.

\begin{tabular}{ccccc}
\hline Item & CON & TR & SEM & $P$-Value \\
\hline $\mathrm{pH}$ & 6.32 & 6.04 & 0.06 & 0.011 \\
Lactate $(\mathrm{mmol} / \mathrm{L})$ & 0.22 & 0.28 & 0.05 & 0.524 \\
Acetate $(\mathrm{mmol} / \mathrm{L})$ & 69.39 & 63.11 & 1.90 & 0.104 \\
Propionate $(\mathrm{mmol} / \mathrm{L})$ & 30.14 & 35.33 & 1.02 & 0.002 \\
Isobutyrate $(\mathrm{mmol} / \mathrm{L})$ & 0.63 & 0.27 & 0.11 & 0.072 \\
Butyrate $(\mathrm{mmol} / \mathrm{L})$ & 13.61 & 11.15 & 0.66 & 0.074 \\
Isovalerate $(\mathrm{mmol} / \mathrm{L})$ & 1.55 & 1.04 & 0.10 & 0.011 \\
Valerate $(\mathrm{mmol} / \mathrm{L})$ & 1.84 & 2.73 & 0.17 & 0.007 \\
Total VFA ${ }^{3}(\mathrm{mmol} / \mathrm{L})$ & 117.16 & 113.63 & 2.75 & 0.520 \\
A: $^{4}$ & 2.33 & 1.79 & 0.09 & 0.001 \\
Acetate $(\%)$ & 59.21 & 55.46 & 0.68 & 0.005 \\
Propionate $(\%)$ & 25.76 & 31.25 & 0.81 & $<0.001$ \\
Butyrate $(\%)$ & 11.58 & 9.68 & 0.40 & 0.018 \\
\hline
\end{tabular}

${ }^{1} \mathrm{CON}$ (control group) = dairy cows fed total mixed ration (TMR). ${ }^{2} \mathrm{TR}$ (treatment group) = dairy cows fed pelleted high-starch diet. ${ }^{3}$ VFA $=$ volatile fatty acid. ${ }^{4} \mathrm{~A}: \mathrm{P}=$ the ratio of acetate to propionate.

Rumination time was lower $(P=0.027)$ in TR group than that in CON group (Table 3$)$. No significant difference was observed in eating and lying time between $\mathrm{CON}$ and TR groups during the monitoring period.

Table 3. Average durations of daily feeding behavior (in minutes) observed in $\mathrm{CON}^{1}$ and $\mathrm{TR}^{2}$ groups.

\begin{tabular}{ccccc}
\hline Item & CON & TR & SEM & $P$-Value \\
\hline Eating & 300.19 & 278.28 & 3.56 & 0.201 \\
Lying & 860.32 & 830.73 & 2.78 & 0.108 \\
Rumination & 380.51 & 305.65 & 3.13 & 0.027 \\
\hline
\end{tabular}

${ }^{1} \mathrm{CON}\left(\right.$ control group) = dairy cows fed total mixed ration (TMR). ${ }^{2} \mathrm{TR}$ (treatment group) $=$ dairy cows fed pelleted high-starch diet.

\subsection{Diversity, Richness and Composition of the Ruminal Bacterial Communities}

The number of operational taxonomic units (OTUs), Chao 1 value, Shannon index and abundance-based coverage estimator (ACE) were lower $(P=0.001, P=0.001, P=0.002, P=0.002)$ in TR group than CON group (Table 4). The results of Principal coordinates analysis (PCoA) profile revealed that the plots in CON and TR groups were definitely detached (Figure 1 ; axis $1+$ axis $2=89.11 \%$ ).

Table 4. Alpha diversity of ruminal bacterial communities of $\mathrm{CON}^{1}$ and $\mathrm{TR}^{2}$ groups.

\begin{tabular}{ccccc}
\hline Item & CON & TR & SEM & $P$-Value \\
\hline Number of OTUs $^{3}$ & 1132 & 544 & 109 & 0.001 \\
ACE $^{4}$ & 1404 & 813 & 112 & 0.002 \\
Chao 1 value & 1416 & 760 & 124 & 0.001 \\
Shannon index & 4.92 & 3.05 & 0.36 & 0.002 \\
\hline
\end{tabular}

${ }^{1} \mathrm{CON}$ (control group) = dairy cows fed total mixed ration (TMR). ${ }^{2} \mathrm{TR}$ (treatment group) = dairy cows fed pelleted high-starch diet. ${ }^{3}$ OTUs $=$ operational taxonomic units. ${ }^{4} \mathrm{ACE}=$ abundance-based coverage estimator. 


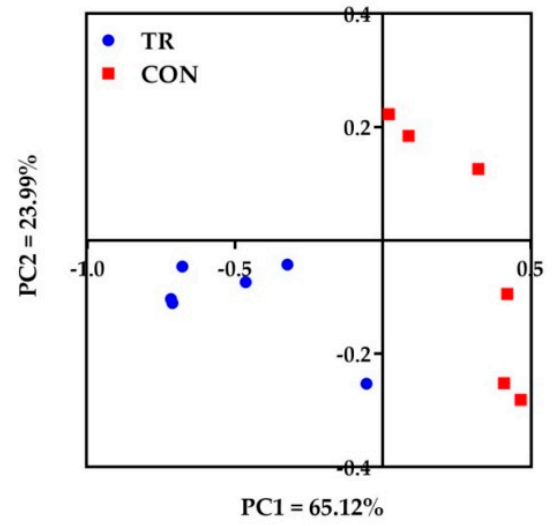

Figure 1. Unweighted UniFrac metric PCoA of microbial diversity in CON and TR groups. The percentage of variation explained by PC1 and PC2 are indicated on the axis.

We identified 22 bacterial phyla in ruminal fluid samples (Table 5). The common of the sequences obtained belonged to Bacteroidetes and Firmicutes. TR group had a higher $(P=0.018)$ relative abundance of Bacteroidetes, with a lower $(P=0.028, P=0.006, P=0.045)$ relative abundance of Firmicutes, Proteobacteria and Candidate_division_TM7 than CON group.

Table 5. The relative abundance of phylum level (\% of total sequences) in ruminal bacterial communities of $\mathrm{CON}^{1}$ and $\mathrm{TR}^{2}$ groups.

\begin{tabular}{ccccc}
\hline \multirow{2}{*}{ Phylum } & \multicolumn{2}{c}{ Relative Abundance (\%) } & \multirow{2}{*}{ SEM } & \multirow{2}{*}{$\boldsymbol{P}$-Value } \\
\cline { 2 - 3 } & CON & TR & & \\
\hline Bacteroidetes & 54.80 & 79.88 & 5.95 & 0.018 \\
Firmicutes & 36.81 & 18.45 & 5.33 & 0.028 \\
Proteobacteria & 5.99 & 0.60 & 1.67 & 0.006 \\
Spirochaetae & 0.56 & 0.30 & 0.15 & 0.522 \\
Cyanobacteria & 0.48 & 0.26 & 0.06 & 0.068 \\
Actinobacteria & 0.19 & 0.19 & 0.03 & 0.855 \\
Candidate_division_TM7 & 0.26 & 0.09 & 0.04 & 0.045 \\
Tenericutes & 0.38 & 0.09 & 0.08 & 0.067 \\
Fibrobacteres & 0.19 & 0.08 & 0.05 & 0.200 \\
Synergistetes & 0.06 & 0.03 & 0.01 & 0.234 \\
Candidate_division_SR1 & 0.17 & 0.03 & 0.04 & 0.120 \\
Planctomycetes & 0.01 & 0.01 & $<0.01$ & 0.571 \\
Gemmatimonadetes & 0.03 & $<0.01$ & 0.01 & 0.107 \\
Acidobacteria & 0.01 & $<0.01$ & 0.01 & 0.284 \\
Others & 0.08 & $<0.01$ & 0.02 & 0.090 \\
\hline
\end{tabular}

${ }^{1} \mathrm{CON}\left(\right.$ control group) $=$ dairy cows fed total mixed ration (TMR). ${ }^{2} \mathrm{TR}$ (treatment group) $=$ dairy cows fed pelleted high-starch diet.

We found 178 taxa across ruminal fluid samples. The abundant taxa (relative abundance of $\geq 0.01 \%$ ) were presented in Table 6 for the purposes of clarity and visualization. The Prevotella taxa was higher $(P=0.018)$, while the unclassified Lachnospiraceae, Oribacterium, unclassified Christensenellaceae, Pseudobutyrivibrio, unclassified Veillonellaceae and unclassified Succinivibrionaceae taxa were lower $(P=0.045, P=0.010, P=0.044, P=0.010, P=0.011, P=0.028)$ in TR group than CON group. No significance in the abundance of Succiniclasticum, Roseburia, Ruminococcus et al. between CON and TR groups. 
Table 6. The relative abundance of ruminal microbiome predominant genera ${ }^{1}$ of $\mathrm{CON}^{2}$ and TR 3 groups.

\begin{tabular}{|c|c|c|c|c|c|}
\hline \multirow{2}{*}{ Phylum } & \multirow{2}{*}{ Genus } & \multicolumn{2}{|c|}{ Relative Abundance (\%) } & \multirow{2}{*}{ SEM } & \multirow{2}{*}{$P$-Value } \\
\hline & & $\mathrm{CON}$ & TR & & \\
\hline \multirow{5}{*}{ Bacteroidetes } & Prevotella & 42.04 & 72.91 & 7.12 & 0.018 \\
\hline & Unclassified Prevotellaceae & 3.10 & 1.66 & 0.40 & 0.144 \\
\hline & Unclassified S24-7 & 4.88 & 3.06 & 1.01 & 0.273 \\
\hline & RC9_gut_group & 2.26 & 1.02 & 0.47 & 0.068 \\
\hline & Unclassified BS11 gut group & 1.42 & 0.61 & 0.42 & 0.100 \\
\hline \multirow{17}{*}{ Firmicutes } & Unclassified Ruminococcaceae & 7.75 & 2.28 & 1.67 & 0.068 \\
\hline & Ruminococcus & 3.61 & 1.83 & 0.78 & 0.361 \\
\hline & Saccharofermentans & 0.66 & 0.36 & 0.16 & 0.201 \\
\hline & Roseburia & 3.99 & 1.41 & 1.34 & 0.100 \\
\hline & Butyrivibrio & 1.99 & 2.25 & 0.43 & 0.855 \\
\hline & Unclassified Lachnospiraceae & 1.62 & 0.68 & 0.27 & 0.045 \\
\hline & Lachnospiraceae_Incertae_Sedis & 1.53 & 0.93 & 0.23 & 0.201 \\
\hline & Oribacterium & 1.00 & 0.10 & 0.20 & 0.010 \\
\hline & Syntrophococcus & 0.86 & 2.22 & 0.38 & 0.144 \\
\hline & Lachnospira & 0.79 & 0.36 & 0.19 & 0.201 \\
\hline & Pseudobutyrivibrio & 0.61 & 0.05 & 0.12 & 0.010 \\
\hline & Selenomonas & 0.97 & 0.40 & 0.21 & 0.100 \\
\hline & Dialister & 0.54 & 0.34 & 0.14 & 0.855 \\
\hline & Unclassified Veillonellaceae & 0.54 & 0.04 & 0.13 & 0.011 \\
\hline & Unclassified Christensenellaceae & 0.99 & 0.19 & 0.26 & 0.044 \\
\hline & Succiniclasticum & 5.64 & 3.51 & 1.05 & 0.201 \\
\hline & Unclassified Erysipelotrichaceae & 0.84 & 0.34 & 0.20 & 0.100 \\
\hline Proteobacteria & $\begin{array}{c}\text { Unclassified } \\
\text { Succinivibrionaceae }\end{array}$ & 4.77 & 0.18 & 1.58 & 0.028 \\
\hline Spirochaetae & Treponema & 0.54 & 0.29 & 0.15 & 0.584 \\
\hline
\end{tabular}

1 Taxa are illustrated in alphabetical order. A taxon is assigned as predominant if its relative abundance is $\geq 1 \%$ in at least one group. ${ }^{2} \mathrm{CON}$ (control group) = dairy cows fed total mixed ration (TMR). ${ }^{3} \mathrm{TR}$ (treatment group) = dairy cows fed pelleted high-starch diet.

\subsection{Predicted Functions of Ruminal Bacterial Microbiota}

This study inferred that 43 gene families were identified in the rumen fluid samples. The gene families of energy metabolism, carbohydrate metabolism, lipid metabolism, amino acids metabolism, signal transduction and translation were the most abundant gene families in the rumen microbiome of both groups (Figure 2). Furthermore, it was noticed that three gene families in the ruminal microbiome showed a significantly different abundance between both groups. When compared with CON group, the gene families involved in the carbohydrate metabolism, energy metabolism and transcription were significantly increased $(P=0.021, P=0.030, P=0.004)$ in TR group. 


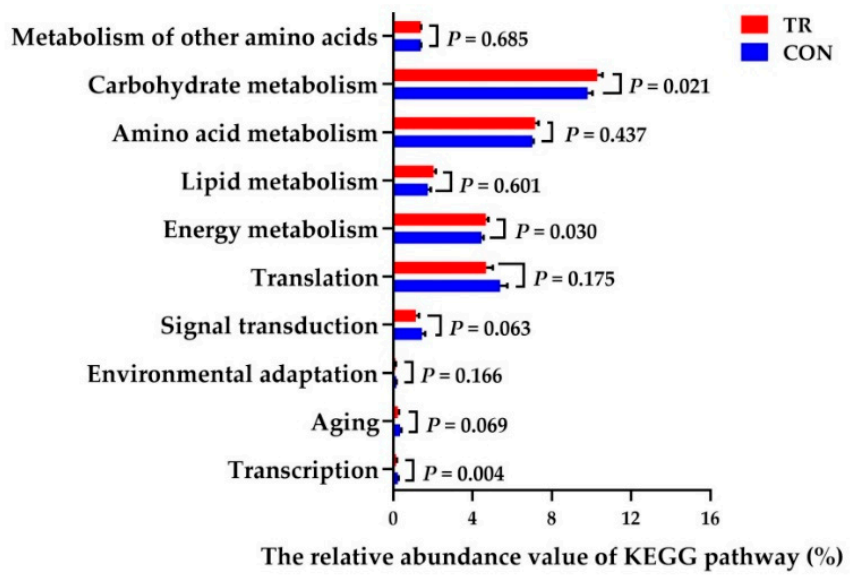

Figure 2. The relative abundance of the top-ten phylogenetic investigation of communities by reconstruction of unobserved states (PICRUSt)-predicted metabolic pathways of ruminal bacterial microbiome in CON and TR groups.

\subsection{Correlation Analysis between the Ruminal VFA Parameters and Microbiome}

Correlation networks were constructed using the data regarding the VFA parameters and the most abundant taxa (relative abundance of $\geq 0.01 \%$ ) based on Spearman correlation coefficients $(|r|>0.60$ and $P<0.05)$ in CON and TR groups (Figure 3$)$. We observed that the concentration of acetate $(P=0.003$, $r=-0.809)$ and butyrate $(P=0.025, r=-0.682)$, the ratio of acetate to butyrate $(P=0.011, r=-0.745)$ had negative correlation with the Prevotella taxa. Acetate concentration $(P=0.011$ and $0.011, r=0.745$ and 0.745$)$ and the ratio of acetate to propionate ( $P=0.022$ and $0.047, r=0.690$ and 0.618$)$ were positively correlated with the Unclassified Ruminococcaceae and Unclassified Lachnospiraceae taxa. We also found that propionate had not high correlation with any other ruminal bacteria. Furthermore, the ratio of acetate to propionate was sensitive to the Prevotella taxa from its correlation value. The Pseudobutyrivibrio taxa had positive correlation with acetate $(P=0.003, r=0.808)$ and butyrate $(P<0.001, r=0.867)$ concentration, but it had no correlation with the ratio of acetate to propionate. 


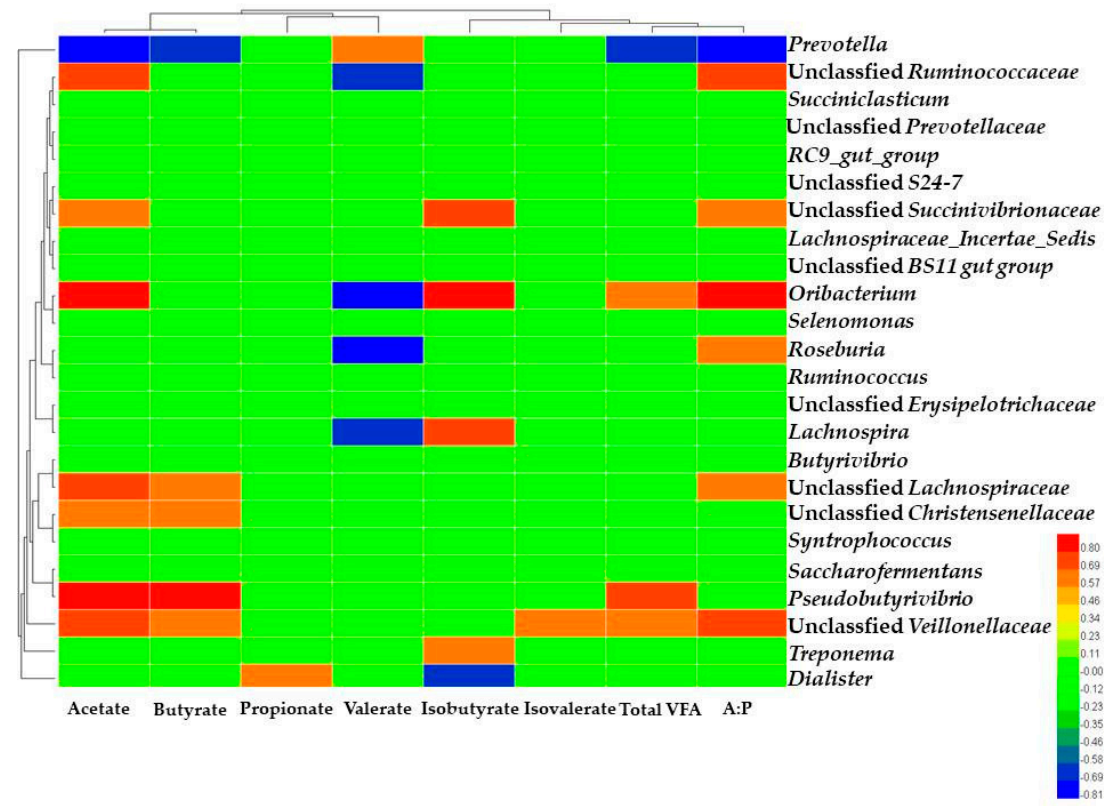

Figure 3. Heat map showing the spearman correlation between ruminal volatile fatty acids (VFA) parameters and microbiome in CON and TR groups. Red means a significant positive correlation, blue means a significant negative correlation and green means a non-significant correlation. The correlation coefficients with a statistical $P$ value $<0.05$ and the absolute value $>0.60$ were used to establish the network graph. A: $\mathrm{P}=$ the ratio of acetate to propionate; VFA = volatile fatty acid.

\subsection{GC/MS Analysis of the Ruminal Fluid}

We detected 665 valid peaks unique in the ruminal fluid sample. We identified 272 metabolites, mainly amines, amino acids, organic acids, fatty acids, lipids, sugars, nucleosides and other metabolites. The metabolites of principal component analysis (PCA) and partial least squares-discriminate analysis (PLS-DA) in CON and TR groups were conducted. As shown in Figure 4, the PCA discovered that the axes 1 and 2 were up to $31.4 \%$ and $14.8 \%$ of the total variation, respectively. The ruminal metabolites in CON and TR groups were clearly distinct, demonstrating the difference of metabolites in the rumen between CON and TR groups.

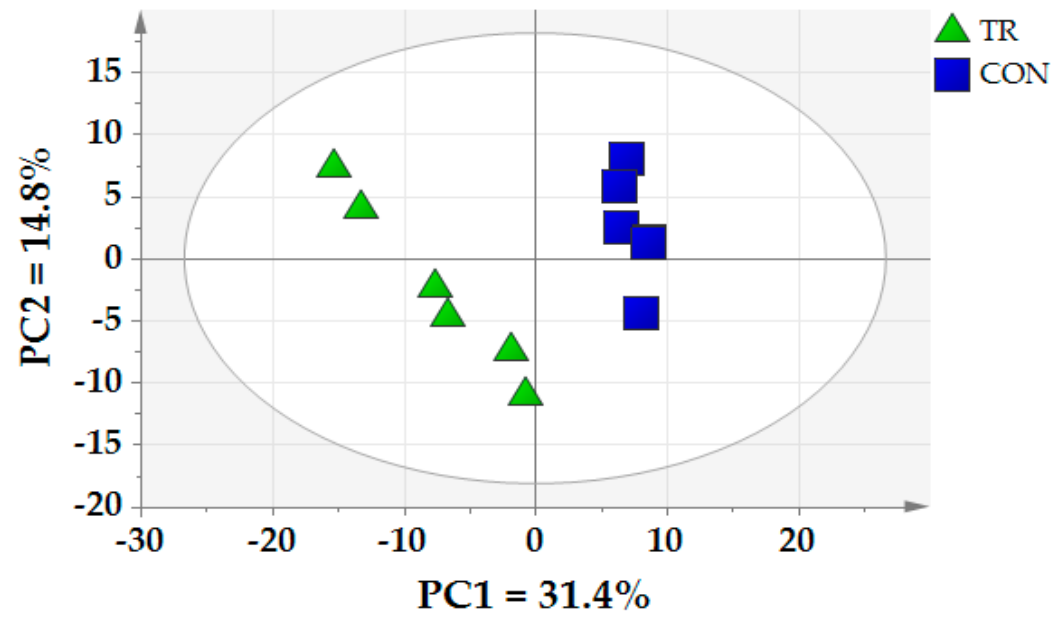

Figure 4. Principal component analysis (PCA) of ruminal metabolites of $\mathrm{CON}$ and TR groups. PC1 $=$ the first principal component; PC2 = the second principal component. 


\subsection{Differences in Ruminal Metabolites between CON and TR Groups}

In total, 29 differential metabolites (DMs) (false discovery rate (FDR) $<0.05$ and variable importance in projection (VIP) $>1$ ) were identified according to the statistical analysis and the VIP value obtained from the PLS-DA analysis. These DMs were classified and the name, the VIP value and the fold change of each metabolite were shown in Table 7. In general, the main difference in ruminal metabolites between $\mathrm{CON}$ and TR groups were the variation of fatty acids, amino acids, lipids, organic acids, sugars, amines, and nucleosides. The content of 23 ruminal metabolites, such as amino acids (glutamine, isoleucine, ornithine, oxyproline, alanine and serine), sugars (6-deoxy-D-glucose and D-talose), amines (N-Acetyl-beta-D-mannosamine, malonamide, 5-methoxytryptamine and indole-3-acetamide), methyl phosphate, pimelic acid, taxifolin and malonate in TR group were higher (FDR $<0.05)$ than CON group.

Table 7. List of ruminal fluid metabolites that showed significant difference between $\mathrm{CON}^{1}$ and $\mathrm{TR}^{2}$ groups $^{3}$.

\begin{tabular}{|c|c|c|c|c|c|c|}
\hline Compounds & $\mathrm{RT}^{4}$ & Mass & VIP $^{5}$ & FDR $^{6}$ & $P$-Value & $\mathrm{FC}^{7}$ \\
\hline \multicolumn{7}{|l|}{ Amino acids } \\
\hline Glutamine & 13.75 & 125 & 1.69 & 0.035 & 0.010 & 1.85 \\
\hline Isoleucine & 10.55 & 158 & 1.535 & 0.043 & 0.026 & 2.148 \\
\hline Ornithine & 16.91 & 174 & 1.558 & 0.046 & 0.041 & 1.948 \\
\hline Oxyproline & 13.61 & 156 & 1.507 & 0.044 & 0.030 & 3.209 \\
\hline Alanine & 7.86 & 116 & 1.672 & 0.046 & 0.042 & 4.227 \\
\hline Serine & 11.44 & 204 & 1.441 & 0.039 & 0.016 & 3.133 \\
\hline \multicolumn{7}{|l|}{ Fatty acids } \\
\hline Malonate & 13.24 & 81 & 1.776 & 0.010 & $<0.001$ & 5.93 \\
\hline Benzoic acid & 10.15 & 179 & 1.519 & 0.043 & 0.028 & 0.557 \\
\hline Pimelic acid & 14.58 & 125 & 2.125 & 0.010 & $<0.001$ & 2.903 \\
\hline Glutaconic acid & 12.6 & 55 & 1.255 & 0.045 & 0.034 & 0.345 \\
\hline $\begin{array}{l}\text { 3-Hydroxyphenylacetic } \\
\text { acid }\end{array}$ & 14.65 & 164 & 1.788 & 0.043 & 0.020 & 0.44 \\
\hline Azelaic acid & 16.72 & 317 & 1.532 & 0.043 & 0.028 & 0.477 \\
\hline \multicolumn{7}{|l|}{ Lipids } \\
\hline Methyl Palmitoleate & 17.98 & 97 & 1.498 & 0.046 & 0.044 & 0.607 \\
\hline Methyl Phosphate & 9.14 & 241 & 1.54 & 0.034 & 0.007 & 12.668 \\
\hline \multicolumn{7}{|l|}{ Sugars } \\
\hline 6-Deoxy-D-glucose & 15.74 & 117 & 1.838 & 0.015 & 0.002 & 3.49 \\
\hline Mannose & 17.53 & 160 & 1.089 & 0.046 & 0.046 & 0.588 \\
\hline D-Talose & 17.84 & 299 & 1.268 & 0.045 & 0.034 & 4.233 \\
\hline \multicolumn{7}{|l|}{ Organic acids } \\
\hline D-galacturonic acid & 18.11 & 333 & 1.408 & 0.046 & 0.046 & 3.234 \\
\hline Salicylic acid & 13.46 & 267 & 2.165 & 0.010 & $<0.001$ & 0.063 \\
\hline Succinic acid & 10.88 & 147 & 1.457 & 0.034 & 0.007 & 2.066 \\
\hline \multicolumn{7}{|l|}{ Amines } \\
\hline N-Acetyl-beta-D-mannosamine & 19.4 & 73 & 1.464 & 0.043 & 0.026 & 1.809 \\
\hline Malonamide & 13.93 & 174 & 1.401 & 0.043 & 0.022 & 2.034 \\
\hline 5-Methoxytryptamine & 22.8 & 174 & 1.714 & 0.045 & 0.036 & 2.049 \\
\hline Indole-3-acetamide & 18.53 & 318 & 1.863 & 0.035 & 0.011 & 19.487 \\
\hline \multicolumn{7}{|l|}{ Nucleosides } \\
\hline Thymine & 12.04 & 255 & 1.923 & 0.046 & 0.039 & 3.574 \\
\hline 2'-Deoxyadenosine & 24.07 & 192 & 1.446 & 0.043 & 0.025 & 3.61 \\
\hline \multicolumn{7}{|l|}{ Other metabolites } \\
\hline Taxifolin & 26.33 & 179 & 1.804 & 0.035 & 0.011 & 31.784 \\
\hline Resorcinol & 11.82 & 239 & 1.614 & 0.039 & 0.016 & 2.505 \\
\hline Alizarin & 23.92 & 192 & 2.018 & 0.038 & 0.013 & 2.407 \\
\hline
\end{tabular}

${ }^{1} \mathrm{CON}$ (control group) = dairy cows fed total mixed ration (TMR). ${ }^{2}$ TR (treatment group) $=$ dairy cows fed pelleted high-starch diet. ${ }^{3} \mathrm{~A}$ metabolite is assigned as significantly different if its VIP is $>1$ with and FDR $<0.05$. ${ }^{4} \mathrm{RT}=$ retention time. ${ }^{5} \mathrm{VIP}=$ variable importance in projection. ${ }^{6} \mathrm{FDR}=$ false discovery rate. ${ }^{7} \mathrm{FC}=$ fold change, the ratio of mean value of peak area obtained from the cows in CON and TR groups. If FC $>1.5$, means that this metabolite is higher in TR group than in CON group. If FC $<0.67$, means that this metabolite is lower in TR group than in CON group. 


\subsection{Metabolic Pathways of Differential Metabolites}

To provide a comprehensive view of the DMs between dairy cows with MFD and the controls, pathway analysis was conducted (Figure 5). Results revealed that glycine, serine and threonine metabolism; biosynthesis of amino-acetyl-tRNA; methane metabolism; amino acids and nucleoside metabolism; arginine and alanine metabolism; glutamate metabolism were significantly enriched (FDR $<0.05$ ) in TR group compared with CON group.

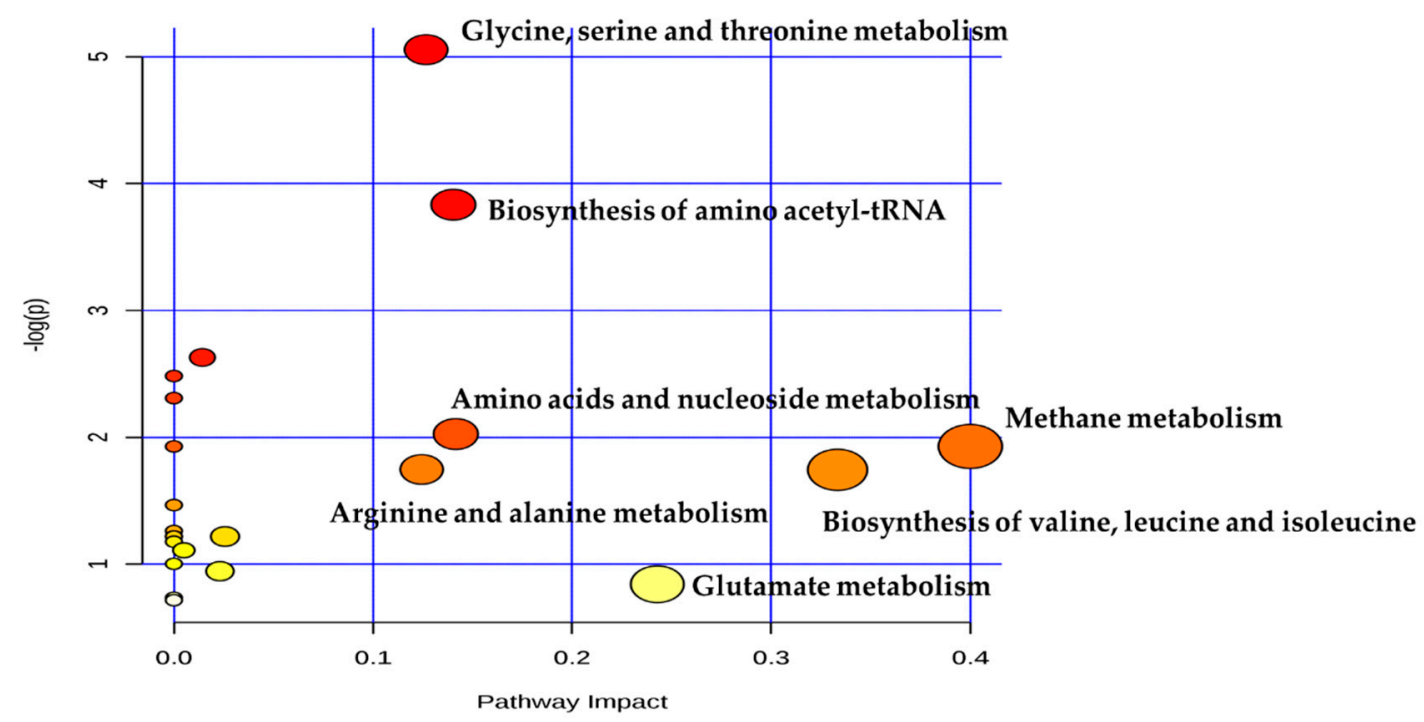

Figure 5. Metabolome view map of the differential metabolites (DMs) (VIP > 1, FDR < 0.05) identified in $\mathrm{CON}$ and TR groups. The larger size indicates higher pathway enrichment, and darker color indicates higher pathway impact values.

\subsection{Correlation Analysis between the Ruminal Microbiome and Metabolome}

Correlation networks were constructed by means of the data concerning the most abundant taxa (relative abundance of $\geq 0.01 \%$ ) and DMs (VIP $>1$ and FDR $<0.05$ ) created on Spearman correlation coefficients $(|\mathrm{r}|>0.75$ and $P<0.05)$ in CON and TR groups (Figure 6). We observed that the top 5 high negative correlations were between the unclassified BS11_gut_group and serine; the RC9_gut_group and oxyproline; Oribacterium and indole-3-acetamide; the RC9_gut_group and 5-methoxytryptamine; the unclassified Lachnospiraceae and glutaconic acid. The top 5 high positive correlations were between Treponema and D-talose; the unclassified Veillonellaceae and 3-hydroxyphenylacetic acid; the Prevotella and methyl phosphate; the Prevotella and succinic acid; the Prevotella and glutaconic acid. The main bacteria were Prevotella, Syntrophococcus, unclassified Veillonellaceae Oribacterium, unclassified Lachnospiraceae, RC9_gut_group and unclassified BS11_gut_group which belong to Bacteroidetes and Firmicutes; the main metabolites were amines (indole-3-acetamide and 5-methoxytryptamine), amino acids (serine and oxoproline), dicarboxylic acid (glutaconic acid), organic acid (succinic acid) and sugars (D-talose). In addition, alanine was negatively $(r=-0.866 ; P=0.021)$ correlated with the Oribacterium. 


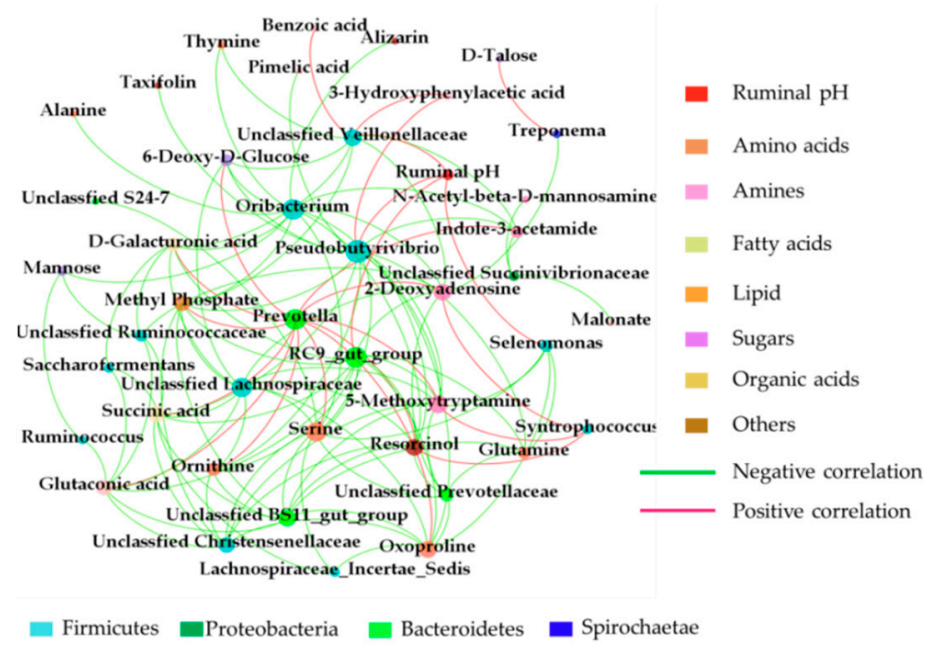

Figure 6. The spearman correlation network between ruminal microbiome and metabolome in CON and TR groups. The correlation coefficients with a statistical $P$ value $<0.05$ and the absolute value $>0.75$ were used to build the network graph.

\section{Discussion}

Fat is the most variable of the major components of ruminant milk, which can be affected by diet and the proportion of ruminal VFA [7]. Previous studies have revealed that there was an association between shifts in the rumen VFA patterns and the decrease in yield of milk fat [7,8]. Coch et al. [8] observed that diet-induced MFD cattle was related to the shifts in molar proportions of ruminal VFA. In consistency with these reports, in the present study, the cows in TR group encountered a decrease in percentage of acetate and butyrate and an increase in propionate percentage compared with CON group. Thus, the main reason for the MFD occurrence could be the decrease in percentage of butyrate and acetate.

Saliva production is an important characteristic of the ruminant digestive process because saliva acts as a buffering agent that helps to preserve optimum $\mathrm{pH}$ levels in the rumen. Saliva secretion occurs continuously but is more secreted during eating and ruminating [9]. Rumination is a natural behavior of foregut fermenting species and it can stimulate the saliva secretion which maintains an optimum rumen environment. By decreasing the forage particle size through pelleting [10], various studies have determined pelleted diets' possessions on the feeding behavior of dairy cows. In this study, compared with TMR, pelleted diet altered the feeding behavior of dairy cows because of its own characteristics, and we found that the rumination time of dairy cows in TR group was decreased compared with CON group, and this was caused by short forage particle size of TR diet. TR diet had a higher proportion of maize with additional higher proportion of corn germ meal and corn husk, which provided large amounts of readily digestible carbohydrates. Mechanical activation and high temperature would change the physical structure of the starch and could enhance the starch degradability in the rumen [11]. In the present study, the ingredients of the TR diet were chopped, ground and pelleted through high exit temperature $\left(84^{\circ} \mathrm{C}\right)$ by the pelleted machine. This result indicated that TR diet could enhance the degradability of starch in the rumen and caused MFD in dairy cows. Expectedly, cows in the TR group had a lower time of rumination, which may cause the lower ruminal $\mathrm{pH}$ which was similar to the previous studies [12,13]. These results indicated that the time of rumination in dairy cows can partially change the ruminal $\mathrm{pH}$ by means of saliva secretion.

The richness and diversity of ruminal bacterial microbiota are important indicators of their normal physiological state. In the present study, the lower Chao 1 and Shannon index in TR group suggested that the microbial community composition was altered and tended to be less diverse of dairy cows in TR group. Belanche et al. [14] found that compared with fiber rich diet, starch rich diet can decrease the bacterial and fungal diversity in the rumen. The reason was certain microorganisms 
were sensitive to nitrogen and rumen ammonia concentration. The accumulation of amines could exert negative effect on the ruminal microbiota. In our study, the metabolites of certain amines were increased in TR group which was consistent with Belanche et al. [14]. We also found that the relative abundance of Bacteroidetes was higher and the Firmicutes and Proteobacteria were lower in TR group in the present study. A replacement of Firmicutes and Proteobacteria by Bacteroidetes was associated with the transition from the forage to concentrate diets [15]. This indicated the Bacteroidetes became the dominant bacteria by the high starch diet. Our results in the present study confirmed the previous reports that Prevotella was the most abundant genus of adult dairy cows [16]. Reduced eating time with increased starch content in diets could result in the high relative abundance of Prevotella, which could be explained by the increased proportion of ruminal fermentable substrates and the reduction in ruminal $\mathrm{pH}$ [17]. Correlation analysis revealed the relative abundance of Prevotella was negatively correlated with the acetate, butyrate concentration and the ratio of acetate to propionate in the present study, which indicated that high relative abundance of Prevotella changed the ruminal fermentation type. The main reason was that TR diet provided larger proportion of ruminal fermentable substrates, changed the ruminal $\mathrm{pH}$ and caused the shift of the ruminal bacterial community composition, which altered the VFA production. In this study, high-starch diet provided large amounts of readily digestible carbohydrates which could increase the relative abundance of Prevotella, and the Prevotella taxa would participate in the carbohydrates digesting process. Meanwhile, the lower ruminal $\mathrm{pH}$ could provide the suitable conditions for Prevotella to survive, which was consistent with James [18]. Consistent with the findings by Liu et al. [19], some higher abundance of unclassified groups, containing unclassified Lachnospiraceae and unclassified Ruminococcaceae were observed in rumen of dairy cattle. Kim et al. [20] found that these two unclassified bacterial groups might play a significant role in fiber digestion of rumen. In the present study, the dairy cows in TR group had lower relative abundance of unclassified Lachnospiraceae and unclassified Ruminococcaceae, correlation analysis revealed that unclassified Lachnospiraceae and unclassified Ruminococcaceae had positive correlation with the acetate concentration and the ratio of acetate to propionate, which indicated that both of the bacteria could be intensively concerned with high starch diets fermentation in the rumen. The ruminal microbiome provides many physiological functions that are required by the host dairy cow. To define the potential functions of the microbiota in ruminal fluid samples, the PICRUSt was used to infer putative metagenomes from the 16S rRNA gene profiles [21]. Results showed that the ruminal microbiota had an enhanced capacity to affect carbohydrate metabolism and energy metabolism, while it had a decreased capacity of transcription and aging of dairy cows in TR group. These results implied that rumen bacteria and its functions could respond quickly to high levels of starch in TR diets, and adapt to the diets by enhancing the carbohydrate and energy metabolism.

Metabolomics analysis revealed that the levels of glutamine, isoleucine, ornithine, oxyproline, alanine and serine were higher in dairy cows of TR group. Trent et al. [22] found that the concentration of alanine was concerned with the demise of Gram-negative and Gram-positive bacteria. In this study, correlation analysis revealed that alanine was negatively correlated with Oribacterium. Therefore, the increased concentration of alanine in the rumen of dairy cows with MFD appeared to be caused by the alternation in the abundance of Oribacterium in this study. From the catabolic pathway of arginine in many microorganisms [23], ornithine has been revealed to be formed by ornithine carbamoyl-transferase. Correlation analysis revealed that the ornithine had high positive correlation with the Prevotella and negative correlation with the Pseudobutyrivibrio. In this study, the metabolism of ornithine was higher in TR group. This finding indicated that the genus of Prevotella and Pseudobutyrivibrio may be correlated with the ornithine production through the catabolic pathway of arginine in dairy cows with MFD. From the present study, the levels of biogenic amines including N-acetyl-beta-D-mannosamine, malonamide, 5-methoxytryptamine, indole-3-acetamide were increased in TR group. Ruminants possibly obtained biogenic amines from both diets and microbial metabolites in the rumen and the biogenic amines were mainly instigated from the decarboxylation of convinced amino acids [24]. Moreover, the enriched pathways including biosynthesis of valine, leucine, 
isoleucine and amino-acetyl-tRNA biosynthesis was also observed in cows of TR group. These findings indicated that ruminal microbial bacteria enhanced amino acids metabolism. The possible explanation for the increase in the amino acid metabolism is supported by the lower ruminal $\mathrm{pH}$, and previous studies revealed that the increased activity of bacterial amino acid decarboxylases was owing to the decreased ruminal $\mathrm{pH}[25,26]$.

For dicarboxylic acids, malonate, pimelic acid, azelaic acid and glutaconic acid were identified in this study. The dicarboxylic acids were produced by the biohydrogenation of the non-conjugated linoleic acids formed from linoleic [27,28]. Previous studies suggested that the rate of bio-hydrogenation in the rumen was linked to the milk fat depression (MFD) [29]. Correlation analysis revealed that the glutaconic acid had a higher negative correlation with unclassified Ruminococcaceae, unclassified Lachnospiraceae and unclassified Christensenellaceae, meanwhile, the benzoic acid and 3-hydroxyphenylacetic acid had a higher positive correlation with the unclassified Veillonellaceae. These results indicated that these unclassified bacteria such as unclassified Ruminococcaceae, unclassified Lachnospiraceae, unclassified Christensenellaceae and unclassified Veillonellaceae may be related with the fatty acids metabolism combined with the rate of bio-hydrogenation. This finding was consistent with Huws [30] who observed that unclassified Clostridiales and Ruminococcaceae exert significant effect on bio-hydrogenation. However, these data did not conclude that these bacteria are definitively elaborate in bio-hydrogenation. Further studies should aim to investigate the exact functions of these bacteria in bio-hydrogenation.

\section{Materials and Methods}

\subsection{Experimental Design and Animals}

The animal experimental design and procedures of this study were supported by the Animal Care and Use Committee of Nanjing Agricultural University following the requirements of the Regulations for the Administration of Affairs Concerning Experimental Animals (The State Science and Technology Commission of P. R. China, 1988. No. SYXK (Su) 2015-0656). Twelve healthy second parity Holstein dairy cows (days in milk $(\mathrm{DIM})=119 \pm 14, \mathrm{BW}=628 \pm 56 \mathrm{~kg}$, mean \pm SD, milk yield $=30-40 \mathrm{~kg} / \mathrm{d}$ ) were randomly allocated into control $(\mathrm{CON}, n=6)$ group and treatment $(\mathrm{TR}, n=6)$ groups. Cows were fed three times daily (0600 h, $1300 \mathrm{~h}$ and $2000 \mathrm{~h}$ ) and milk yield and feed intake were recorded every day. Cows were housed in individual tie-stalls fitted with rubber mats and had continuous access to water from water bowls during the experiment. The whole experimental period lasted for 55 days, and all the samples were collected from day 51 to 55 of the experimental period.

\subsection{Diets and Feeding}

The experimental diets were formulated according to the lactation nutritional requests of a $30 \mathrm{~kg}$ milk/d producing cow (NRC, 2001). Dairy cows in CON group were fed TMR, while cows in TR group were fed pelleted high-starch TMR diet. We allowed approximately $5 \%$ feed residual during the experiment period. The pelleted ration was pelleted with a pelleting machine (Jiangsu Muyang Group Co., Ltd., Jiangsu, China) with steam added at an $84{ }^{\circ} \mathrm{C}$ exit temperature. Pellet diameter was $0.63 \mathrm{~cm}$ and the length was $1.75 \mathrm{~cm}$. The chemical composition and ingredients of diets are presented in Table 8. 
Table 8. Ingredient and chemical composition of $\mathrm{CON}^{1}$ and $\mathrm{TR}^{2}$ diets ( $\mathrm{DM}^{3}$ basis).

\begin{tabular}{lcc}
\hline \multicolumn{1}{c}{ Item } & CON & TR \\
\hline Ingredient, \% & & \\
Barley & 2.43 & - \\
DDGS ${ }^{\prime}$ & 2.21 & - \\
Puffed soybean & 2.81 & - \\
Cottonseed & 4.54 & - \\
Beet pulp & 3.70 & - \\
Alfalfa hay & 17.76 & - \\
Corn silage & 18.59 & - \\
Fermented corn flour & 5.05 & - \\
Molasses & 2.46 & - \\
Oat hay & 3.78 & 7.69 \\
Maize & 19.23 & 31.78 \\
Vitamin and mineral mix 5 & 3.26 & 3.26 \\
Soya bean meal & 14.18 & 11.05 \\
Corn germ meal & - & 23.10 \\
Corn husk & - & 15.07 \\
Soybean skin & - & 8.05 \\
Chemical composition & & \\
Moisture, \% & 53.08 & 10.43 \\
CP, \% & 16.96 & 16.78 \\
NDF, \% & 28.17 & 32.33 \\
ADF, \% & 15.09 & 15.19 \\
Ether extract, \% & 4.28 & 4.19 \\
Starch, \% & 16.52 & 21.59 \\
NE, Mcal/kg & 1.57 & 1.63 \\
NFC $\%$, & 42.47 & 8.35 \\
Ash, \% & 8.12 & \\
\hline
\end{tabular}

${ }^{1} \mathrm{CON}$ (control group) $=$ total mixed ration (TMR). ${ }^{2} \mathrm{TR}$ (treatment group) $=$ pelleted high-starch diet. ${ }^{3} \mathrm{DM}=$ dry matter. ${ }^{4}$ DDGS = distillers Dried Grains with Soluble. ${ }^{5}$ Vitamin and mineral mix = formulated to contain $0.83 \% \mathrm{Ca}$; $0.34 \% \mathrm{P} ; 2.8 \% \mathrm{Mg} ; 3.5 \% \mathrm{~K} ; 1500 \mathrm{mg} / \mathrm{kg}$ of Fe; $1500 \mathrm{mg} / \mathrm{kg}$ of Cu; $1495 \mathrm{mg} / \mathrm{kg}$ of Mn; $7000 \mathrm{mg} / \mathrm{kg}$ of Zn; $90 \mathrm{mg} / \mathrm{kg}$ of I; $20 \mathrm{mg} / \mathrm{kg}$ of Co; $50 \mathrm{mg} / \mathrm{kg}$ of Se; $500000 \mathrm{IU} / \mathrm{kg}$ of vitamin A; $130000 \mathrm{IU} / \mathrm{kg}$ of vitamin D; $1210 \mathrm{mg} / \mathrm{kg}$ of vitamin E. ${ }^{6} \mathrm{NFC}=$ non-fiber carbohydrate calculated by difference $100-(\% \mathrm{NDF}+\% \mathrm{CP}+\%$ Fat $+\% \mathrm{Ash})$.

\subsection{Sampling and Analysis}

Feeding behavior analysis. Two monitors (AW-W815ZL4-Y; Guangdong; China) were used for monitoring the behavior $(24 \mathrm{~h} / \mathrm{d}$ ) of dairy cows ( 6 cows each) on the 51st, 52 nd and 53rd day of the experimental period. Each monitor's data recorded the time that cows spent eating, lying or ruminating and then were summed each day.

\subsection{Feed Sampling and Analysis}

Feed and residual samples were collected at $0600 \mathrm{~h}, 1300 \mathrm{~h}$ and $2000 \mathrm{~h}$ after each milking on the 51st, 52nd and 53rd day of the experimental period. Furthermore, samples were kept at $-20{ }^{\circ} \mathrm{C}$ until chemical composition analysis. Crude protein, moisture, starch, ash and ether extract were measured according to the AOAC methods [31]. Acid detergent fiber (ADF) and neutral detergent fiber (NDF) were measured followed by Van Soest et al. [32] (Table 8).

\subsection{Milk Sampling and Analysis}

Milk samples were collected at $0600 \mathrm{~h}, 1300 \mathrm{~h}$ and $2000 \mathrm{~h}$ after each milking on the 51st, 52nd and 53rd day of the experimental period. Sections were reserved at $4{ }^{\circ} \mathrm{C}$, using borneol as a conserving and were sent to Shanghai DHI organization (China) for analyzing. The content of fat, protein and lactose of milk were measured by a near-infrared analyzer (Foss Electric, Denmark). 


\subsection{Ruminal Fluid Sampling and Analysis}

Ruminal fluid samples were collected through oral stomach tube (OST) [33] for 2 consecutive days at $6 \mathrm{~h}$ after morning feeding once per day on the 54th and 55th day of the experimental period. In order to obtain representative ruminal fluid samples, the insertion depth of the OST from the animal's incisors teeth to central rumen was $2 \mathrm{~m}$ according to the method of Shen, Chai, Song, Liu and $\mathrm{Wu}$ [33]. The ruminal fluid was collected about $40 \mathrm{~mL}$ through spontaneous efflux after aspirating with a modified $60 \mathrm{~mL}$ syringe and strained through 4 layer cheesecloth. The ruminal fluid $\mathrm{pH}$ was measured directly using a calibrated $\mathrm{pH}$ meter (Starter 300; Ohaus Instruments Co. Ltd., Nanjing, China). Samples were kept at $-80^{\circ} \mathrm{C}$ until analyzed for fermentation parameters, microbial DNA extraction and GC/MS analysis. The rumen filtrate was thawed and centrifuged at $3000 \times g$ for $10 \mathrm{~min}$. Gas chromatography (7890A, Agilent, Palo Alto, CA, USA) was utilized for VFA analysis followed by Mao et al. [34]. The lactate level was detected by a lactic acid assay kit (Nanjing Bioengineering Institute, China).

\subsection{Microbial DNA Extraction and High-Throughput Sequencing}

Bead-beating approach followed by phenol-chloroform extraction was utilized to ensure an efficient extraction of the total microbial DNA, this protocol had been described by Mao et al. [35]. Nanodrop spectrophotometer (Nyxor Biotech; Paris, France) was used to detect DNA yield and quality. Ultimately, high-quality DNA samples were kept at $-80^{\circ} \mathrm{C}$ for high-throughput sequencing. The V3-V4 region of the $16 \mathrm{~S}$ ribosomal RNA (rRNA) bacterial genes was amplified using $\left(341 \mathrm{~F}=5^{\prime}\right.$-CCTAYGGGRBGCASCAG-3'; $806 \mathrm{R}=5^{\prime}$-GGACTACCVGGGTATCTAAT-3') primers . The barcode was a sample-unique sequence of 6 bases. PCR was conducted based on the Accuprime Taq DNA polymerase System (Invitrogen, Carlsbad, CA), which includes an initial denaturation at $95^{\circ} \mathrm{C}$ for $2 \mathrm{~min}, 30$ cycles of $20 \mathrm{~s}$ denaturation at $95^{\circ} \mathrm{C}, 20 \mathrm{~s}$ annealing at $60^{\circ} \mathrm{C}$, and $60 \mathrm{~s}$ extension at $65{ }^{\circ} \mathrm{C}$, and a $65{ }^{\circ} \mathrm{C}$ extension for $7 \mathrm{~min}$ [36]. The amplicons from each DNA sample were fluorometrically quantified, normalized, and pooled. Finally, 454 GS FLX Titanium chemistry platform (Majorbio Bio-Pharm Technology, Shanghai, China) was utilized for DNA sequencing.

QIIME software platform (http://qiime.org/) [37] was used for the microbial data analysis. According to the previously assigned sample-specific barcodes, high quality sequences were carefully chosen after decoding. Length of fragments more than $250 \mathrm{bps}$ without unknown bases and average score of quality higher than 25 were taken as criteria to select sequences. OTU picking was performed based on 97\% level sequence comparison, using UPARSE [38]. The representative sequence of each OTU was identified as the most abundant sequence in an OTU, and then the most abundant sequences of all OTUs were allocated to the Green genes 13.5 core set [37].

Ribosomal Database Project Bayesian classifier was used to perform the taxonomy assignment [39] via the contrasting of descriptive sequences in each OTU with the Green genes database [40]. QIIME (http://qiime.org/) software package was utilized for evaluating the ACE, Chao1, Shannon, and Simpson. Unweighted Unifrac metric PCoA was measured utilizing MOTHUR (https://www.mothur.org) program [41]. The 16S sequencing data were acquiesced to the Sequence Read Archive (SRA) under consent PRJNA534384.

\subsection{Predicted Rumen Functions of Bacterial Microbiota}

To more deeply understand the rumen functions of bacterial microbiota, we used PICRUSt to predict the metagenomics involvement of the detected communities [21].

\subsection{Metabolomics Analysis}

For metabolite analysis, $200 \mu \mathrm{L}$ ruminal fluid containing $10 \mu \mathrm{L}$ of adonitol as an internal standard was extracted with $350 \mu \mathrm{L}$ methanol and vortexed for $30 \mathrm{~s}$. Samples were centrifuged at 12,000 rpm for $15 \mathrm{~min}$ at $4{ }^{\circ} \mathrm{C}$. After centrifugation, $350 \mu \mathrm{L}$ of the supernatant was evaporated to dryness using 
vacuum concentrator without heating. After evaporation, $50 \mu \mathrm{L}$ of methoxide was added into amination hydrochloride followed by $30 \mathrm{~min}$ incubation at $80^{\circ} \mathrm{C}$ condition. Meanwhile, $70 \mu \mathrm{L}$ of chlorotrimethylsilane silylating reagent was added into the aliquots after $1.5 \mathrm{~h}$ incubation at $70{ }^{\circ} \mathrm{C}$. A gas chromatography system (Agilent 7890, Palo Alto, CA, USA) coupled with a Pegasus HT (LECO, Shanghai, China) time-of-flight mass spectrometer (GC-TOF-MS) was used to identify the metabolites fitted with a DB-5MS capillary column $(30 \mathrm{~m} \times 250 \mu \mathrm{m}$ inner diameter, $0.25 \mu \mathrm{m}$ film thickness; J\&W Scientific, Folsom, CA, USA). $1 \mu \mathrm{L}$ aliquot of the analyte was injected in splitless mode. Helium was used as the carrier gas, the front inlet purge flow was $3 \mathrm{~mL} \mathrm{~min}^{-1}$, and the gas flow rate through the column was $1 \mathrm{~mL} \mathrm{~min}^{-1}$. The primary temperature was kept at $50{ }^{\circ} \mathrm{C}$ for $1 \mathrm{~min}$, then raised to $310^{\circ} \mathrm{C}$ at a rate of $10^{\circ} \mathrm{C} \mathrm{min}^{-1}$, and finally kept for $8 \mathrm{~min}$ at $310^{\circ} \mathrm{C}$. Chroma TOF $4.3 \mathrm{X}$ software and LECO-Fiehn Rtx 5 database (Shanghai Biotreee biotech Co. Ltd., Shanghai, China) were used for raw peaks exacting, the data baselines filtering and calibration of the baseline, peak alignment, deconvolution analysis, peak identification and integration of the peak area. LECO-Fiehn Rtx-5 database was utilized to identify metabolites.

\subsection{Statistical Analysis}

Data of feeding behavior, milk yield, DMI, milk composition and ruminal fermentation parameters were analyzed through the independent sample t-test procedures (SPSS v. 20, SPSS Inc., Chicago, IL, USA). The non-parametric Kruskal-Wallis test was carried out to test for significant variation in the relative abundance of microbiota and the predicted KEGG pathways (\%) (SPSS v. 20, SPSS Inc., Chicago, IL, USA). $P<0.05$ was defined as statistical significance.

SIMCA-P $\mathrm{P}^{+} 13.0$ software (Umea, Sweden) was utilized for conducting multivariate statistical analysis together with PCA. DMs between both groups were identified combining VIP, FDR and FC $(\mathrm{TR} / \mathrm{CON}$ ) acquired from PLS-DA analysis and statistical analysis (VIP $>1, \mathrm{FDR}<0.05$ and FC $>1.5$ or $<0.67)$. To ensure data quality, quality control samples were inserted randomly. Data for DMs were then exported into the MetaboAnalyst web server (https://www.metaboanalyst.ca/) to explore its metabolic pathway spreading and enrichment analysis [42]. The FC (TR/CON) was the ratio of mean value of peak area gained from cows in CON and TR groups.

Correlations between ruminal VFA parameters and the relative abundance of microbiota were calculated using Spearman's correlation test implemented in XLStat (Addinsoft, Paris, France). Heml 1.0.3.3 (Heatmap Illustrator) software was used to visualize the correlation that had a correlation coefficient absolute value greater than 0.60 and significance less than 0.05 .

Correlations between metabolites and microbiota were calculated using Spearman's correlation test implemented in XLStat (Addinsoft, Paris, France). Gephi 0.8.2 software (https://gephi.org/) was used to envision the correlation between microbiota and metabolites that had a correlation coefficient absolute value greater than 0.75 and significance less than 0.05 .

\section{Conclusions}

In the present study, under the condition of dairy cows encountering MFD, the richness and diversity of the ruminal microbiota were significantly reduced, and ruminal fermentation and the bacterial community composition were altered. Metabolomics analysis revealed that some ruminal metabolites were significantly changed, which increased glucose, amines, amino acids and short chain fatty acids. Moreover, correlation analysis revealed some associations between the microbial bacteria and the metabolites. Overall, high-starch diet reduced the rumination time and changed the composition of ruminal bacteria and metabolites, altered rumen fermentation type, and caused MFD.

Author Contributions: Conceptualization, H.Z. and S.M.; methodology, H.Z.; software, H.Z.; formal analysis, H.Z.; investigation, H.Z.; resources, S.M.; writing —original draft preparation, H.Z.; writing-review and editing, C.G., H.S., D.S. and S.M.; supervision, S.M.; project administration, S.M.; funding acquisition, S.M.

Funding: This research was funded by National Key Research and Development Program of China (2018YFD0501600) and the Fundamental Research Funds for the Central Universities (JCQY201905). 
Acknowledgments: Thanks to the dairy farm for allowing us to conduct the experiment and the feed mill that produced pellets.

Conflicts of Interest: The authors declare no conflict of interest.

\section{References}

1. Weimer, P.; Stevenson, D.; Mertens, D. Shifts in bacterial community composition in the rumen of lactating dairy cows under milk fat-depressing conditions. J. Dairy Sci. 2010, 93, 265-278. [CrossRef] [PubMed]

2. Rico, D.E.; Preston, S.H.; Risser, J.M.; Harvatine, K.J. Rapid changes in key ruminal microbial populations during the induction of and recovery from diet-induced milk fat depression in dairy cows. Br. J. Nutr. 2015, 114, 358-367. [CrossRef] [PubMed]

3. Pitta, D.; Indugu, N.; Vecchiarelli, B.; Rico, D.; Harvatine, K. Alterations in ruminal bacterial populations at induction and recovery from diet-induced milk fat depression in dairy cows. J. Dairy Sci. 2018, 101, $295-309$. [CrossRef] [PubMed]

4. Urrutia, N.; Bomberger, R.; Matamoros, C.; Harvatine, K. Effect of dietary supplementation of sodium acetate and calcium butyrate on milk fat synthesis in lactating dairy cows. J. Dairy Sci. 2019, 102, 5172-5181. [CrossRef] [PubMed]

5. Nocek, J.E. Bovine Acidosis: Implications on Laminitis. J. Dairy Sci. 1997, 80, 1005-1028. [CrossRef]

6. Plaizier, J.; Krause, D.; Gozho, G.; McBride, B. Subacute ruminal acidosis in dairy cows: The physiological causes, incidence and consequences. Vet. J. 2008, 176, 21-31. [CrossRef]

7. Sutton, J. Altering Milk Composition by Feeding. J. Dairy Sci. 1989, 72, 2801-2814. [CrossRef]

8. Koch, L.; Jenkins, T.; Bridges, W.; Koch, B.; Lascano, G. Changes in fermentation and animal performance during recovery from classical diet-induced milk fat depression using corn with differing rates of starch degradability. J. Dairy Sci. 2019, 102, 5079-5093. [CrossRef]

9. Maekawa, M.; Beauchemin, K.; Christensen, D. Effect of Concentrate Level and Feeding Management on Chewing Activities, Saliva Production, and Ruminal pH of Lactating Dairy Cows. J. Dairy Sci. 2002, 85, 1165-1175. [CrossRef]

10. Woodford, S.; Murphy, M. Effect of Forage Physical Form on Chewing Activity, Dry Matter Intake, and Rumen Function of Dairy Cows in Early Lactation. J. Dairy Sci. 1988, 71, 674-686. [CrossRef]

11. Jurjanz, S. Ruminal degradability of corn forages depending on the processing method employed. Anim. Res. 2005, 54, 3-15. [CrossRef]

12. Bal, M.; Shaver, R.; Jirovec, A.; Shinners, K.; Coors, J. Crop Processing and Chop Length of Corn Silage: Effects on Intake, Digestion, and Milk Production by Dairy Cows. J. Dairy Sci. 2000, 83, 1264-1273. [CrossRef]

13. Schwab, E.; Shaver, R.; Shinners, K.; Lauer, J.; Coors, J. Processing and Chop Length Effects in Brown-Midrib Corn Silage on Intake, Digestion, and Milk Production by Dairy Cows. J. Dairy Sci. 2002, 85, 613-623. [CrossRef]

14. Belanche, A.; Doreau, M.; Edwards, J.E.; Moorby, J.M.; Pinloche, E.; Newbold, C.J. Shifts in the Rumen Microbiota Due to the Type of Carbohydrate and Level of Protein Ingested by Dairy Cattle Are Associated with Changes in Rumen Fermentation. J. Nutr. 2012, 142, 1684-1692. [CrossRef] [PubMed]

15. Fernando, S.C.; Purvis, H.T.; Najar, F.Z.; Sukharnikov, L.O.; Krehbiel, C.R.; Nagaraja, T.G.; Roe, B.A.; DeSilva, U. Rumen Microbial Population Dynamics during Adaptation to a High-Grain Diet. Appl. Environ. Microbiol. 2010, 76, 7482-7490. [CrossRef] [PubMed]

16. Stevenson, D.M.; Weimer, P.J. Dominance of Prevotella and low abundance of classical ruminal bacterial species in the bovine rumen revealed by relative quantification real-time PCR. Appl. Microbiol. Biotechnol. 2007, 75, 165-174. [CrossRef] [PubMed]

17. Kljak, K.; Pino, F.; Harvatine, K.J.; Heinrichs, A.J. Analysis of selected rumen microbial populations in dairy heifers limit fed diets varying in trace mineral form and starch content. Livest. Sci. 2017, 198, 93-96. [CrossRef]

18. Russell, J.B.; Wilson, D.B. Why are ruminal cellulolytic bacteria unable to digest cellulose at low $\mathrm{pH}$ ? J. Dairy Sci. 1996, 79, 1503-1509. [CrossRef]

19. Liu, J.H.; Zhang, M.L.; Xue, C.X.; Zhu, W.Y.; Mao, S.Y. Characterization and comparison of the temporal dynamics of ruminal bacterial microbiota colonizing rice straw and alfalfa hay within ruminants. J. Dairy Sci. 2016, 99, 9668-9681. [CrossRef] 
20. Kim, H.; Lee, I.; Kwon, Y.; Kim, B.C.; Ha, S.; Lee, J.-H.; Kim, J. Immobilization of glucose oxidase into polyaniline nanofiber matrix for biofuel cell applications. Biosens. Bioelectron. 2011, 26, 3908-3913. [CrossRef]

21. Langille, M.G.I.; Zaneveld, J.; Caporaso, J.G.; McDonald, D.; Knights, D.; Reyes, J.A.; Clemente, J.C.; Burkepile, D.E.; Thurber, R.L.V.; Knight, R.; et al. Predictive functional profiling of microbial communities using 16S rRNA marker gene sequences. Nat. Biotechnol. 2013, 31, 814-821. [CrossRef] [PubMed]

22. Trent, M.S.; Stead, C.M.; Tran, A.X.; Hankins, J.V. Diversity of endotoxin and its impact on pathogenesis. J. Endotoxin Res. 2006, 12, 205-223. [CrossRef] [PubMed]

23. Crow, V.L.; Thomas, T.D. Arginine metabolism in lactic streptococci. J. Bacteriol. 1982, 150, $1024-1032$. [PubMed]

24. Phuntsok, T.; Froetschel, M.A.; Amos, H.E.; Zheng, M.; Huang, Y.W. Biogenic amines in silage, apparent post-ruminal passage, and the relationship between biogenic amines and digestive function and intake by steers. J. Dairy Sci. 1998, 81, 2193-2203. [CrossRef]

25. Bailey, S.R.; Rycroft, A.; Elliott, J. Production of amines in equine cecal contents in an in vitro model of carbohydrate overload. J. Anim. Sci. 2002, 80, 2656. [CrossRef] [PubMed]

26. Khafipour, E.; Li, S.; Plaizier, J.C.; Krause, D.O. Rumen Microbiome Composition Determined Using Two Nutritional Models of Subacute Ruminal Acidosis. Appl. Environ. Microbiol. 2009, 75, 7115-7124. [CrossRef]

27. Ward, P.; Scott, T.; Dawson, R. The hydrogenation of unsaturated fatty acids in the ovine digestive tract. Biochem. J. 1964, 92, 60-68. [CrossRef]

28. Sachan, D.S.; Davis, C.L. Hydrogenation of linoleic acid by a rumen spirochete. J. Bacteriol. 1969, 98, 300-301.

29. Jenkins, T.C.; Wallace, R.J;; Moate, P.J.; Mosley, E.E. BOARD-INVITED REVIEW: Recent advances in biohydrogenation of unsaturated fatty acids within the rumen microbial ecosystem1. J. Anim. Sci. 2008, 86, 397-412. [CrossRef]

30. Huws, S.A.; Scott, M.B.; Tweed, J.K.S.; Scollan, N.D.; Kim, E.J.; Lee, M.R.F.; Pinloche, E.; Wallace, R.J. As yet uncultured bacteria phylogenetically classified as Prevotella, Lachnospiraceae incertae sedis and unclassified Bacteroidales, Clostridiales and Ruminococcaceae may play a predominant role in ruminal biohydrogenation. Environ. Microbiol. 2011, 13, 1500-1512. [CrossRef]

31. AOAC (Association of Official Analytical Chemists). Official Methods of Analysis; AOAC: Rockville, MD, USA, 1990.

32. Van Soest, P.; Robertson, J.; Lewis, B. Methods for Dietary Fiber, Neutral Detergent Fiber, and Nonstarch Polysaccharides in Relation to Animal Nutrition. J. Dairy Sci. 1991, 74, 3583-3597. [CrossRef]

33. Shen, J.; Chai, Z.; Song, L.; Liu, J.; Wu, Y. Insertion depth of oral stomach tubes may affect the fermentation parameters of ruminal fluid collected in dairy cows. J. Dairy Sci. 2012, 95, 5978-5984. [CrossRef] [PubMed]

34. Mao, S.; Zhang, G.; Zhu, W. Effect of disodium fumarate on ruminal metabolism and rumen bacterial communities as revealed by denaturing gradient gel electrophoresis analysis of 16S ribosomal DNA. Anim. Feed. Sci. Technol. 2008, 140, 293-306. [CrossRef]

35. Mao, S.; Zhang, R.; Wang, D.; Zhu, W. The diversity of the fecal bacterial community and its relationship with the concentration of volatile fatty acids in the feces during subacute rumen acidosis in dairy cows. BMC Vet. Res. 2012, 8, 237. [CrossRef] [PubMed]

36. Kittelmann, S.; Seedorf, H.; Walters, W.A.; Clemente, J.C.; Knight, R.; Gordon, J.I.; Janssen, P.H. Simultaneous Amplicon Sequencing to Explore Co-Occurrence Patterns of Bacterial, Archaeal and Eukaryotic Microorganisms in Rumen Microbial Communities. PLoS ONE 2013, 8, e47879. [CrossRef]

37. Campbell, B.J.; Polson, S.W.; Hanson, T.E.; Mack, M.C.; Schuur, E.A.G. The effect of nutrient deposition on bacterial communities in Arctic tundra soil. Environ. Microbiol. 2010, 12, 1842-1854. [CrossRef] [PubMed]

38. Edgar, R.C. Search and clustering orders of magnitude faster than BLAST. Bioinformatics 2010, 26, $2460-2461$. [CrossRef]

39. Wang, Q.; Garrity, G.M.; Tiedje, J.M.; Cole, J.R. Naïve Bayesian Classifier for Rapid Assignment of rRNA Sequences into the New Bacterial Taxonomy. Appl. Environ. Microbiol. 2007, 73, 5261-5267. [CrossRef]

40. DeSantis, T.Z.; Hugenholtz, P.; Larsen, N.; Rojas, M.; Brodie, E.L.; Keller, K.; Huber, T.; Dalevi, D.; Hu, P.; Andersen, G.L. Greengenes, a Chimera-Checked 16S rRNA Gene Database and Workbench Compatible with ARB. Appl. Environ. Microbiol. 2006, 72, 5069-5072. [CrossRef] 
41. Schloss, P.D.; Westcott, S.L.; Ryabin, T.; Hall, J.R.; Hartmann, M.; Hollister, E.B.; Lesniewski, R.A.; Oakley, B.B.; Parks, D.H.; Robinson, C.J.; et al. Introducing mothur: Open-Source, Platform-Independent, Community-Supported Software for Describing and Comparing Microbial Communities. Appl. Environ. Microbiol. 2009, 75, 7537-7541. [CrossRef]

42. Xia, J.; Psychogios, N.; Young, N.; Wishart, D.S. MetaboAnalyst: A web server for metabolomic data analysis and interpretation. Nucleic Acids Res. 2009, 37, W652-W660. [CrossRef] [PubMed]

(C) 2019 by the authors. Licensee MDPI, Basel, Switzerland. This article is an open access article distributed under the terms and conditions of the Creative Commons Attribution (CC BY) license (http://creativecommons.org/licenses/by/4.0/). 